\title{
THE VALUE OF THE VON PIRQUET TEST AS CON- TROLLED BY NECROPSY FINDINGS *
}

\author{
J. H. MASON KNOX, JR., Ph.D., M.D. \\ BALTIMORE
}

The object of this paper is to report the results of a study of the von Pirquet cutaneous test for tuberculosis on a series of children who have died and on whom careful necropsies have been performed. It is felt that in this way alone a conclusive judgment as to the value of the von Pirquet reaction in making a positive diagnosis of the presence or absence of tuberculosis can be acquired, for postmortem examination offers the only absolute verification of the diagnosis of tuberculosis.

Many investigations of this reaction have been made in this country on children from infancy through school age, in which the results of the test, whether positive or negative, have been confirmed by painstaking physical examination, or by means of the Roentgen ray - very exceptionally by the determination of tubercle bacilli. The discovery of tubercle bacilli, of course, must be accepted as indubitable evidence of the presence of tuberculous infection, but the examination of the chest by the most refined methods at our disposal assisted by Roentgen rays is still a gross and unsatisfactory method of establishing the absence or presence of tuberculosis in doubtful cases, and therefore cannot be used to verify with absolute certainty the value of the vorn Pirquet reaction. Confirmatory evidence of the reliability of this test has been furnished by a number of writers who have shown that the percentage of positive reactions in children increases with their age; that the danger from spreading and fatal tuberculosis is in inverse ratio to the age of the patient, and that tuberculous infection under two years is rarely recovered from.

Thus Rogers, ${ }^{1}$ who followed fifty of the sixty-nine children with positive von Pirquet reactions after their discharge from the Massachusetts General Hospital, found that of the seventeen under 2 years of age, 65 per cent. died, whereas of the thirty-three over 2 years, but 21 per cent. succumbed in from one to four years.

The comparative infrequency of tuberculosis among young infants was shown by Voronin, who examined 140 infants between 2 days

* Submitted for publication May 28, 1917.

* Read at the meeting of the American Pediatric Society, White Sulphur Springs, W. Va., May 28, 1917.

1. Rogers, O. F.: A Study of Children with Positive Skin Tuberculin Reactions, Boston Med. and Surg. Jour., 1915, 172, 161.

2. Voronin, M. S.: Tuberculin Skin Reactions, Russk. Vrach., 1915, 14, 12, 280. 
and 4 months of age, and obtained only two positive von Pirquet reactions.

Brown $^{3}$ performed the test on 650 children, 164 of whom were under 6 months, and of these, twenty reacted positively and all but one died.

Veeder and Johnston ${ }^{4}$ as the result of von Pirquet tests on a large number of schoolchildren in St. Louis, between 10 and 14 years, found that 44 per cent. reacted positively to the von Pirquet test, as compared to 90 per cent. found by Hamburger in a similar investigation among children in Vienna. Veeder's results have been confirmed in many American cities and would indicate that tuberculosis, though all too prevalent, is less widespread in America than in most of the cities of Europe. This is probably due to the more favorable hygienic surroundings in this country, as Keifet $z^{5}$ has found that the positive von Pirquet reaction was obtained twice as frequently among children living among unfavorable surroundings as among those living in an environment described as favorable.

Von Pirquet's ${ }^{6}$ report on the value of the cutaneous test for tuberculosis in children, is based on the examination of about 2,000 children. Of these, 200 died and came to necropsy. Of the fatal cases, 109 had no tuberculous lesions, while in eighty-nine, foci of tuberculosis were found, and two had doubtful lesions. The 109 children found at necropsy to be free from tuberculosis had negative skin reactions. Of the eighty-nine cases shown to have tuberculous lesions at necropsy, sixty had positive von Pirquet tests and twenty-nine had negative reactions. In the negative cases the reaction was made during measles, or on patients extremely ill with spreading or advanced lesions of tuberculosis.

The present study is based on investigation of the fatal cases that have come to necropsy from the Harriet Lane Home, of the Johns Hopkins Hospital, service of Dr. Howland, to whom I am indebted for the use of his material, from November, 1912, to April, 1917. In this time there were approximately 2,940 cases admitted to the wards. with 750 deaths. Of this number, careful necropsies were performed on 324 infants and children, from birth to 12 years of age.

These necropsy cases have been analyzed with reference to the von Pirquet reaction. Sixty-eight cases were found to have tuberculous lesions on postmortem examination, that is, about 20 per cent. of

3. Brown, A.: Am. Jour. Obst., 1913, 68, 377.

4. Veeder, B. S., and Johnston, M. R.: The Frequency of Infection with the Tubercle Bacilli in Childhood, Am. Jour. Dis. Child., 1915, 9, 478.

5. Keifetz, M. N.: Cutaneous Tuberculin Test in School Children, Jour. Am. Med. Assn., 1915, 65, 1412.

6. Von Pirquet, C.: Summarized in Cleveland Med. Jour., 1908, 7, 585. 
the fatal cases examined after death. Two hundred and fifty-six, or 80 per cent., were found at postmortem examination to be free from tuberculosis.

This incidence of tuberculosis in infancy and childhood agrees with the results of Veeder's investigations and is much smaller than is reported in European centers. As has been repeatedly found, the number of tuberculous cases increased rapidly with the age of the patient.

The tuberculous and the nontuberculous cases have been tabulated according to age and color and. with reference to the von Pirquet reaction.

TABLE 1.-Tuberculous Cases at Necropsy

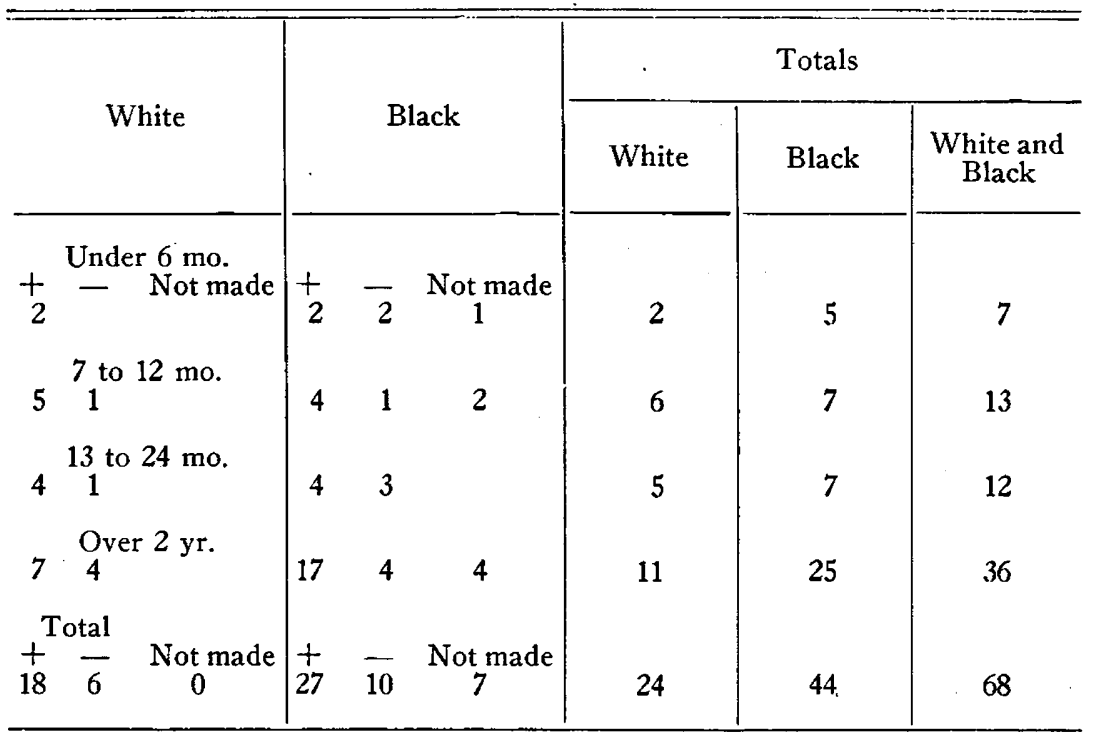

This test was made, where performed at all, as a routine measure by the ward intern.' Koch's old tuberculin, undiluted, was used and the scarification done by the borer devised by von Pirquet. Readings were made in twenty-four and forty-eight hours. Of the 256 cases having no tuberculous lesions at necropsy, the test was made in 172 instances. It was never positive, but negative without exception.

On the original inspection of this series, there were four cases thought to be positive, but in carefully reviewing the histories it was found that in three instances, although the first test had been doubtful, a second confirmative test was negative, and in the fourth case, a patch of fibrous pleurisy, probably tuberculous, accounted for the postive skin reaction. 
It should be emphasized that no doubtful cases should be called positive, but the test should be repeated; and only those called positive in which there is a marked contrast between the tuberculin treated areas and the control site. This result seems to furnish most reliable confirmatory evidence among American children that a properly performed von Pirquet reaction which is constantly negative precludes the possibility of tuberculous infection, except in extremely ill children.

Of the sixty-eight cases in which tuberculous lesions were found at necropsy, the von Pirquet reaction was made in sixty-one; of these, it resulted positively in forty-five cases and negative in sixteen. The negative cases were carefully analyzed. In twelve instances the

TABLE 2.-Non-Tuberculous Cases at Necropsy

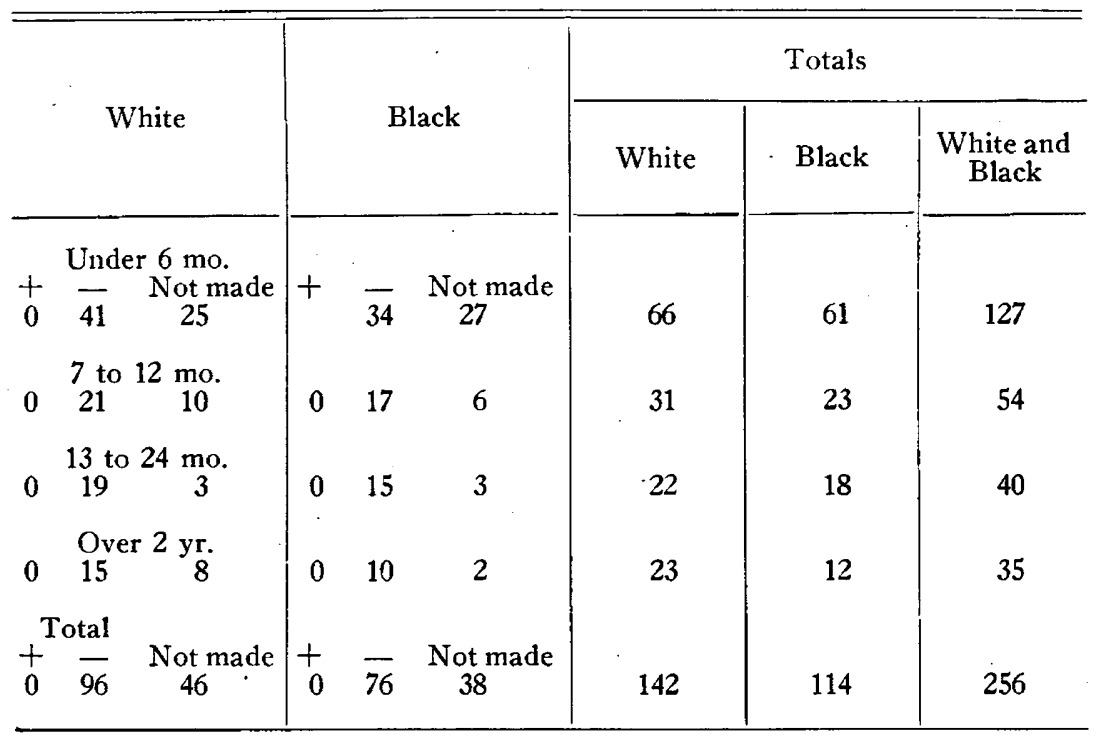

patients were suffering from rapidly advaacing widespread miliary tuberculosis, in two instances from tuberculous meningitis, in two from pulmónary tuberculosis of advanced stage with cavity formation, and in one instance from tuberculous peritonitis. In all instances the test had been made from a week to a few days before death, usually several weeks after the onset of illness.

It can be fairly concluded, therefore, from our figures, that as asserted by von Pirquet and repeatedly confirmed by other investigators, that a positive cutaneous test indicates the presence of a tuberculous lesion, but that a negative test in patients extremely ill, overwhelmed by the toxin of tuberculosis, especially in those suffering from miliary tuberculosis, may frequently fail to react positively. In 
other words, a negative test, except in extremely ill patients in which the physical examination would probably determine the presence of tuberculosis, usually indicates the absence of tuberculous lesions, whereas a positive reaction in every instance shows the presence of tuberculosis. None of the patients in our series had measles.

The tabulation of the tuberculous cases shows that forty-four of the sixty-eight cases are colored, and twenty-four white; and of the seven fatal cases under 6 months, five are colored, and two white. These results would strengthen the view that tuberculosis is much more prevalent among the black than among the white races, in proportion to their population, and that the tuberculous infection occurs at an earlier period of life in the black.

It may be concluded from these results here reported that the cutaneous test with tuberculin, as described by von Pirquet, is a most reliable aid in the detection of tuberculosis in children; that a positive reaction indicates invariably a tuberculous focus in the body; and that a persistently negative reaction establishes the fact that there is no tuberculous lesion except in those extremely ill patients where the presence of tuberculosis can be readily established by physical examination. 